\title{
RASO DE CHIROLÍ: UNA NECRÓPLIS TUMULAR EN LOS ALCORES (CARMONA, SEVILLA)
}

\section{RASO DE CHIROLÍ: A TUMULAR NECROPOLIS AT LOS ALCORES (CARMONA, SEVILLA)}

\author{
por
}

MILAGROSA SANCHEZ ANDREU

\begin{abstract}
RESUMEN En el presente artículo se describen dos sepulturas de incineración bajo túmulo. Fueron excavadas en 1909 por Bonsor en la zona de los Alcores (Carmona, Sevilla) y forman parte de una necrópolis desconocida hasta ahora, la del Raso del Chirolí.

ABSTRACT In this article, two incineration burials under tumulus are described. These were excavated by G.Bonsor in the Alcores's area in 1909 and they form part of a necropolis unknown up to now "Raso del Chiroli".
\end{abstract}

Las sepulturas prerromanas de Los Alcores fueron muy pronto objeto de interés para los eruditos locales, entre los que podemos citar a Felipe Méndez, que con anterioridad a 1885 había excavado doce de los túmulos de la necrópolis de Bencarrón. Pero, sin duda, el más destacado de los investigadores del momento es G. Bonsor, quien inició también por esas fechas sus exploraciones. Ya en 1884 trabajó en el Campo de las Canteras, y al año siguiente lo hacía en Bencarrón. Desde ese momento sus investigaciones se suceden en Los Alcores hasta 1898 (Raddatz y Carriazo, 1960: 5).

En 1902 y hasta 1904 vuelve a excavar en Bencarrón y Gandul. Los años siguientes los dedicará a las labores de limpieza y acondicionamiento del Castillo de Mairena del Alcor (Raddatz y Carriazo, 1960: 6) y a participar en algunas de las excursiones que lleva a cabo la Sociedad Arqueológica de Carmona (Soc. Arqu. Carm.,1884: 36 y 57).

En 1908 Bonsor inicia nuevas investigaciones en las necrópolis de Bencarrón, Acebuchal y Ranilla, y al año siguiente en el olivar llamado "Raso del Chirolî".

La necrópolis de El Raso del Chirolí está situada a la izquierda de la carretera que comunica El Viso del Alcor con Carmona, a la altura del Km. 517 y a unos $200 \mathrm{~m}$. de las primeras casas de la primera localidad citada. Es muy posible que en la actualidad, el crecimiento del pueblo haya provocado la destrucción de las sepulturas. 
En el olivar, Bonsor encontró siete colinas tumulares a las que nombró con las letras A a G, pero sólo recoge noticias de tres: las A, C y D (Bonsor, 1908-1912: 25).

La necrópolis de El Raso del Chirolí está en las cercanías del hábitat de Mesa de Tablada (Amores, 1979-80: 365 y 1982: 90), al igual que la vecina de Santa Lucía, pero carecemos de datos precisos que nos permitan asegurar la vinculación, tanto de una como de otra, a este núcleo de población. Por ahora, nos hemos de limitar a señalar tal posibilidad (Fig. 2).

En el presente trabajo describiremos las colinas tumulares exploradas durante el año 1909 en esta necrópolis '. Los datos que ofrecemos han sido extraídos de los "Cuadernos de Excavación" de Bonsor, en los que se recogen de forma breve, y un tanto desordenada, los resultados de las exploraciones que efectuaba. De la mayor parte de las excavaciones en Los Alcores posteriores a 1898 son los "Cuadernos" la única fuente de información que poseemos, ya que estos enterramientos nunca fueron objeto de una monografía similar a la publicada en 1899 (Bonsor, 1899).

\section{Túmulo A}

Ocupaba la parte más elevada del olivar y era, según los datos de Bonsor, el de mayor tamaño de la necrópolis (Bonsor, 1908-1912: 25 y 26) (Fig.3). Albergaba un enterramiento de incineración en el que la cremación del cuerpo se efectuó en una pira levantada directamente sobre el suelo rocoso (Fig. 4.1). Esta, de forma rectangular, estaba orientada en dirección N.E-S.O. No tenemos ninguna información sobre sus dimensiones ni sobre el tipo de maderas con el que se construyó.

Los huesos y las cenizas aparecieron mezclados con los restos de la combustión, y todo ello cubierto por los fragmentos de un ánfora "con depresión en la zona central" (Bonsor, 1908-1912: 26) (Fig. 4.2). Este recipiente es similar a las llamadas "de saco", y se corresponde con el tipo A de la tabla de ánforas fenicias e iberopúnicas del Cerro Macareno. Tiene una cronología que abarca desde el s. VII al V a. C. (Pellicer y otros, 1983: 84 y sig.).

Bonsor no halló ningún elemento de ajuar acompañando al enterramiento (Bonsor, 1908-1912: 26).

La sepultura se cubrió con un túmulo que no es descrito de una forma directa por su descubridor, aunque proporciona un dibujo del alzado lo suficientemente expresivo como para poder establecer sus características generales (Fig. 4.1).

Sobre el quemadero se observa la existencia de un pequeño túmulo de $0^{\prime} 40 \mathrm{~m}$. de potencia, cubierto a su vez por un estrato de tierras y piedras de $1 \mathrm{~m}$. de altura. La capa se cierra con un nivel de piedras de diverso tamaño desigualmente repartidas por la superficie de la estructura. Por encima de ésta, continúa el estrato de tierras y piedras hasta alcanzar la altura definitiva del túmulo, 2'60 m. Desconocemos el diámetro de la colina artificial.

\section{Túmulo C}

Fue explorado también durante 1909 mediante una trinchera abierta en la parte central, pero a diferencia del A y del D no ofreció ningún tipo de hallazgo. Bonsor no lo excavó completamente y tampoco recogió detalles sobre la naturaleza de la estructura tumular, por lo que desconocemos, incluso, si ésta tenía carácter artificial (Fig. 3).

1. El presente artículo ha sido extraído de la Memoria de Licenciatura que con el título de Aproximación a los rituales funerarios de las necrópolis tumulares de los Alcores, (Carmona, Sevilla) se realizó en el marco del Proyecto de Investigación FUNUS, subvencionado por la Consejería de Educación de la Junta de Andalucía. Fue defendida en la Universidad de Cádiz durante 1990. 


\section{Túmulo D}

Este túmulo, al igual que el A, cubre una sepultura de incineración. La pira, de forma rectangular, se levantó directamente sobre el suelo. Estaba orientada en dirección N.E.-S.O. (Bonsor, 1908-1912: 27) (Fig. 4.3).

Según Bonsor, la cremación fue completa, ya que entre los abundantísimos restos de carbones apenas aparecieron algunos fragmentos de huesos de muy pequeño tamaño. No halló entre ellos ningún objeto de ajuar (Bonsor, 1908-1912: 27).

Una capa de piedras planas sirvió para cubrir la pira ya consumida, y sobre ellas se levantó el túmulo definitivo. Estaba compuesto por una sola capa de tierra y alcanzaba 1'15 m. de altura (Bonsor, 1908-1912: 27). Desconocemos su diámetro.

De los túmulos restantes (B, E, F y G) no hemos hallado noticia alguna en los "Cuadernos de Excavación". Ignoramos si éstos fueron explorados alguna vez. Los marcados con las letras E, F y G son los más pequeños de todo el conjunto y es probable que, ante los pobres resultados obtenidos en los mayores, Bonsor renunciara a excavarlos. El F aparece marcado con una interrogación en uno de los planos del investigador (Fig. 3), pero es difícil establecer la causa.

El túmulo B es, sin embargo, uno de los mayores de la necrópolis y además se encuentra muy próximo al $\mathrm{A}$, pero a pesar de todo carecemos de la más mínima información sobre su suerte.

\section{ESTUDIO DE LOS RITUALES FUNERARIOS}

\section{Estructuras}

Los dos túmulos descritos albergaban unas estructuras muy simples, ya que la pira para la cremación se levantó, en ambas ocasiones, directamente sobre el suelo.

Este tipo de sepulturas no es desconocido en las necrópolis de Los Alcores. Las hallamos con seguridad en Alcaudete (Bonsor, 1899: 60) y en algunas de las colinas tumulares menores de Bencarrón (Bonsor, 1899: 48 y sig.). La asignación a esta categoría resulta más dudosa para las sepulturas B, C y F de Acebuchal (Bonsor, 1899: 27-28), la de Huerta Nueva (Bonsor, 1899: 70), la E del Campo de las Canteras (Bonsor, 1899: 107) y dos de las incineraciones de la Cañada de las Cabras (Bonsor, 1899: 73). Bonsor las califica de "emplazamientos de piras", pero emplea estos términos indistintamente para las incineraciones en fosa y para las que se realizan sobre el suelo (Bonsor, 1899: 27).

Como cobertura se utiliza, en el caso de la sepultura del túmulo $\mathrm{A}$, restos cerámicos correspondientes a un ánfora. Este comportamiento tiene paralelos muy próximos en los túmulos $\mathrm{A}, \mathrm{B}, \mathrm{C}$ y $\mathrm{F}$ de Acebuchal (Bonsor, 1899: 27), en el de Alcantarilla (Bonsor, 1899: 50) y en todas las sepulturas conocidas de Alcaudete (Bonsor, 1899: 60). También es frecuente en Los Alcores la cobertura a base de piedras de tamaño variable. Como paralelos podemos citar varios de los túmulos de Bencarrón, el del Olivo, el de la Dehesa (Bonsor, 1902: 12, 22, 66 y 71) y el B y D (Bonsor, 1908-1912: 19 y sig.). Las piedras cubren también la sepultura del C del Campo de las Canteras (Bonsor, 1899: 68 y 69).

Podemos concluir diciendo que las estructuras de los enterramientos de El Raso parecen corresponderse con el mundo funerario observado en Los Alcores. Los paralelos más próximos estarían en la 
vecina necrópolis de Acebuchal (túmulos $\mathrm{B}, \mathrm{C}$ y F) y en Alcaudete para el túmulo A. El D del Raso del Chirolí tiene correspondencia exacta con las sepulturas B y D de la necrópolis de Bencarrón, en los que no hay referencia alguna a la presencia o ausencia de fosa (Bonsor, 1908-1912: 19 y sig) (Fig. 5).

\section{Rituales}

Las piras se levantaron directamente sobre el suelo, es decir, ni se excavó ni se construyó infraestructura alguna para albergarlas. Esto no excluye, por supuesto, la posibilidad de algún tipo de preparación previa, que podría abarcar desde la limpieza de vegetación de los alrededores a rituales más elaborados y de los que no nos quedaría constancia arqueológica alguna.

Las piras de las sepulturas de El Raso estuvieron orientadas en dirección N.E.- S.O. Esto parece ser lo habitual, pero tenemos muy pocos elementos de juicio para establecer alguna hipótesis de comportamiento fiable en las incineraciones de Los Alcores. Sólo nos ha llegado información sobre los quemaderos del túmulo A de Acebuchal, del I del Judío y del túmulo del Olivo en Bencarrón, todos ellos con la misma orientación que los de El Raso. En los túmulos de la Dehesa de Bencarrón, Ruiz Sánchez y Alcantarilla la fosa que albergaba la pira se excavó en dirección E.- O. Como podemos observar, la orientación no varía mucho, pero este comportamiento uniforme se rompe en los casos en los que conocemos la disposición del cadáver sobre la pira. Así, encontramos el cuerpo con la cabeza al S.O. en las sepulturas A de Acebuchal y en el túmulo del Olivo en Bencarrón; hacia el O. en el túmulo de la Dehesa y en dirección E. en Ruiz Sánchez y Alcantarilla; por lo que la aparente uniformidad debe referirse sólo a la construcción de los ustrina y nunca a la colocación del cuerpo. Es posible que la orientación esté en función de la línea del Alcor, pero la dificultad para identificar las sepulturas excavadas por Bonsor no permite por el momento la comprobación de esta hipótesis.

En cuanto a los rituales que debieron acompañar a la incineración del cadáver, quisiera llamar la atención sobre la existencia de restos anfóricos cubriendo numerosas sepulturas de Los Alcores, entre ellas la del túmulo A de El Raso. Es posible que estos recipientes se trasladasen hasta el lugar de la cremación para transportar algún líquido (agua o vino) empleado en ritos de libaciones u ofrendas. Los fragmentos de las ánforas servirían después para formar la cobertura, separando así los restos de la combustión de la tierra del túmulo.

El difunto se deposita sobre la pira acompañado, en ocasiones, por el ajuar o al menos por parte de él. No es éste el caso de las sepulturas de El Raso, ya que en ninguna de ellas apareció objeto alguno que pudiera considerarse como tal. No podemos excluir la posibilidad de que existiera algún tipo de ofrenda que no hubiese soportado la acción del fuego y del tiempo.

Una vez concluido el proceso de combustión, los restos óseos permanecen en el mismo lugar mezclados con las cenizas y cubiertos por una capa de piedras, cerámicas o tierra limpia (Bonsor, 1899: 44). Este parece ser el comportamiento habitual en las incineraciones de Los Alcores, ya que sólo conocemos dos enterramientos, el del túmulo II de Bencarrón y el del $\mathrm{C}$ del Campo de las Canteras, en los que las sepulturas definitivas no coinciden con el lugar donde se efectuó la cremación (Bonsor, 1899: 40 y 69).

\section{El Túmulo}

Las sepulturas del Raso del Chirolí están cubiertas por colinas artificiales cuyas dimensiones son similares a las halladas sobre las incineraciones del entorno de Los Alcores. Los túmulos que cobijan incineraciones tienen unas alturas que oscilan entre los $50 \mathrm{~cm}$. (como el de Méndez en Bencarrón) y los 4 m. (Ruiz Sánchez y Alcantarilla). 
En cuanto al sistema constructivo, la alternancia de capas de tierra y niveles de piedras las encontramos en el túmulo de la Dehesa de Bencarrón (Bonsor, 1902: 71-72), en el de Ruiz Sánchez (Bonsor, 1899: 58), en los de Ranilla (Amores, 1982: 117 y sig.) o en el túmulo A del Campo de las Canteras (Belén y otros, 1987: 421). No son infrecuentes, tampoco, estructuras más sencillas, como las del túmulo D, similares a las que cubrían algunas de las sepulturas de incineración de la necrópolis de Bencarrón (Bonsor, 1899: 41, 48-49). De las mismas características debieron ser las del túmulo II, uno de los excavados por Méndez en Bencarrón (Bonsor, 1899: 44 y sig.; Amores, 1982: 93) y las de Huerta Nueva (Bonsor 1899: 70).

\section{CRONOLOGIA}

Es difícil determinar con exactitud una fecha para estos enterramientos. La ausencia de ajuar es completa, y sólo tenemos para datar el ánfora utilizada como cobertura en el túmulo A. Este recipiente tiene una cronología amplia, del VII al V a. C. (Pellicer y otros, 1983). El ámbito cronológico que establece es en el que, habitualmente, se sitúan los túmulos orientalizantes de Los Alcores, aunque las sepulturas sin marfiles suelen considerarse algo más tardías (Blanco, 1960. Blázquez, 1968. Almagro Gorbea, 1974. Aubet, 1980: 48. 1981-82: 233. Cerdeño, 1981. Amores, 1982).

\section{BIBLIOGRAFIA}

ALMAGRO GORBEA, M. (1974): “Los campos de túmulos de Pajaroncillo (Cuenca). Aportación al estudio de los túmulos de la Península Ibérica”. E.A.E. n. ${ }^{\circ} 83$.

AMORES, F. (1979-80): "El poblamiento orientalizante en Los Alcores (Sevilla): Hipótesis de un comportamiento", Habis X-XI: 361-374.

(1982): Carta arqueológica de Los Alcores (Sevilla). Diputación de Sevilla. Sevilla.

AUBET, M. E. (1980): "Marfiles fenicios del Bajo Guadalquivir. II Acebuchal y Alcantarilla", Studia Archaeologica 63 .

(1980-1981): “Marfiles fenicios del Bajo Guadalquivir. III Bencarrón, Santa Lucía y Setefilla”, Pyrenae 1718: $231-279$.

BELEN, M., LINEROS, R., PUYA, M. (1987): "Excavaciones en la necrópolis de Carmona (Sevilla)", Anuario arqueológico de Andalucía. Actividades Sistemáticas. T. II: 417-423.

BLANCO, A. (1960): “Orientalia II”. A.E.A. n.ำ 101-102: 3-43.

BLAZQUEZ, J. M. (1968): Tartessos y los orígenes de la colonización fenicia en Occidente. Salamanca.

BONSOR, G. E. (1899): "Les colonies agricoles pré-romaines de la vallée du Betis", Revue Archéologique XXV. (1902): Exploration archéologique des Alcores. Fouilles á Bencarrón et a Gandul 190 . Cuaderno A. (Manuscrito conservado en el Archivo Histórico de Andalucía).

(1908-1912): Fouilles archéologiques des Alcors. 1900-1912. Libro E. (Manuscrito conservado en el Archivo Histórico de Andalucía).

CERDEÑO, M. L. (1981): "Los broches de cinturón tartésicos", Huelva Arqueológica V: 31-56. SOCIEDAD ARQUEOLOGICA DE CARMONA.

(1984): Actas de las Sesiones y Papeles de la Sociedad Arqueológica de Carmona. Documentos conservados en el Museo Arqueológico de Carmona.

PELLICER, M., ESCACENA, J. L., BENDALA, M. (1983): “El Cerro Macareno”. A.E.A., n.. 129.

RADDATZ, K., CARRIAZO, J de M.

(1960): "Primicias de un corte estratigráfico en Carmona", Archivo Hispalense 103-104 (separata). 


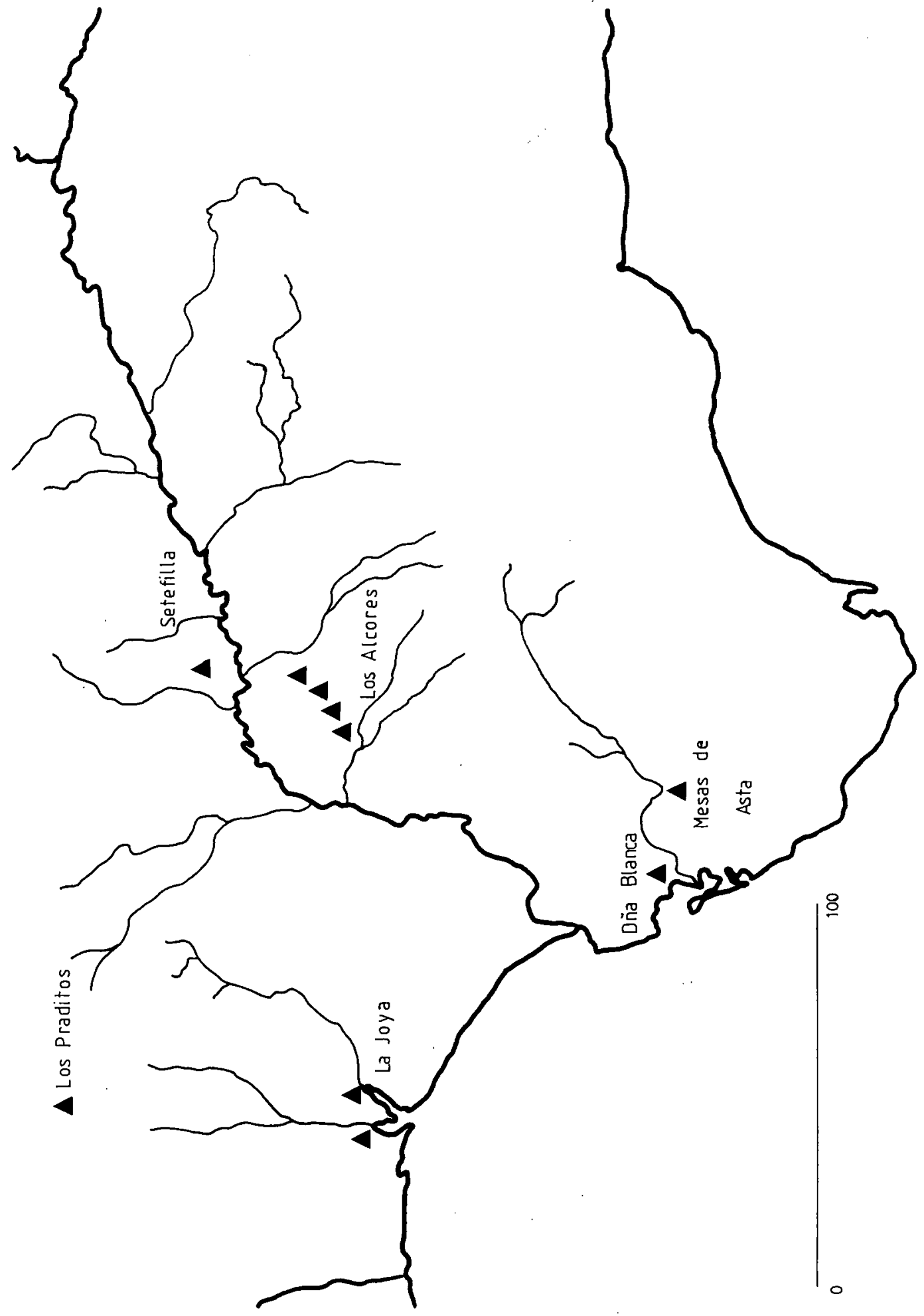

Fig. I. Los Alcores (Carmona) y los yacimientos con necrópolis tumulares. 


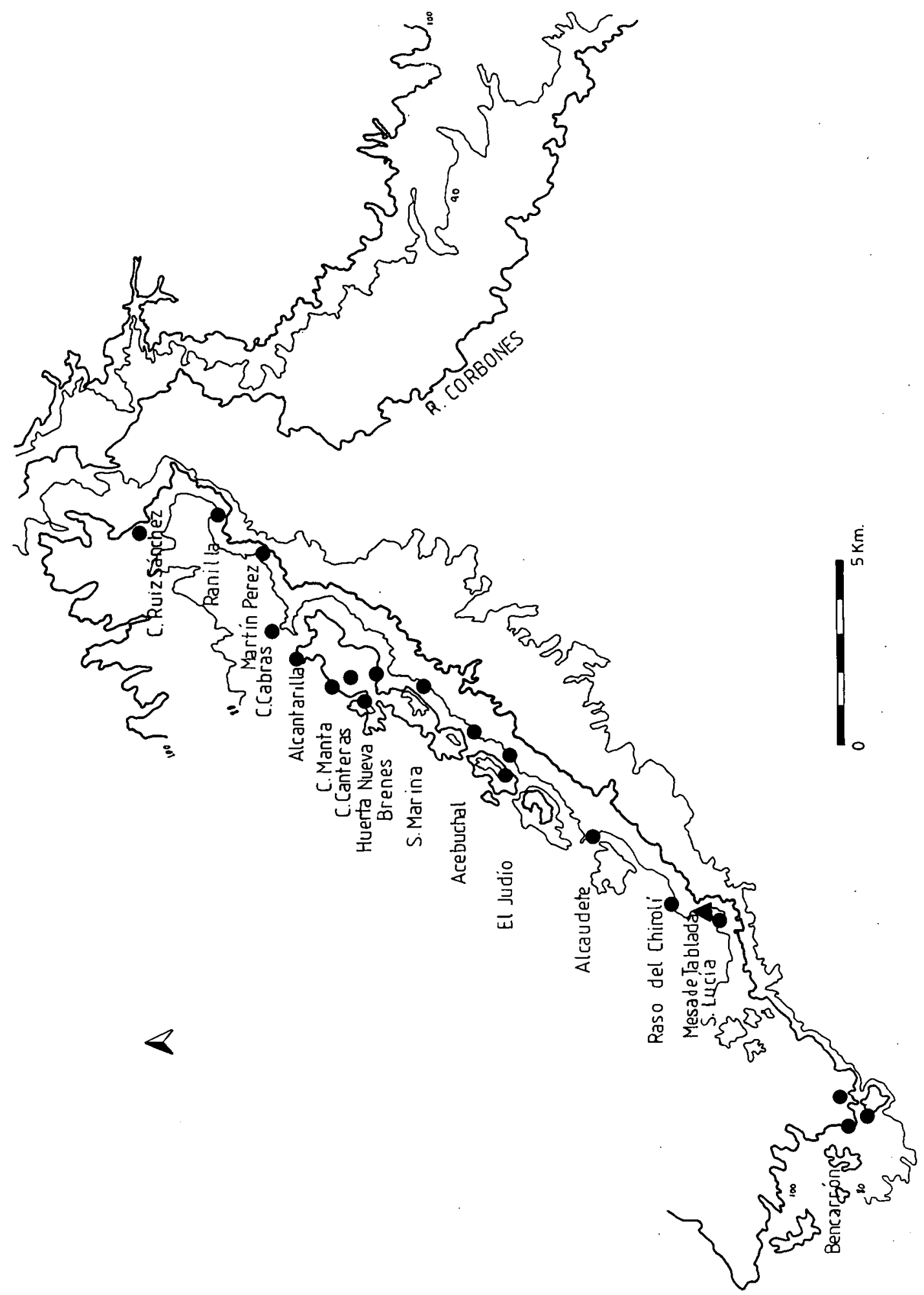

Fig. 2. Situación de la necrópolis de El Raso del Chirolí en Los Alcores. 


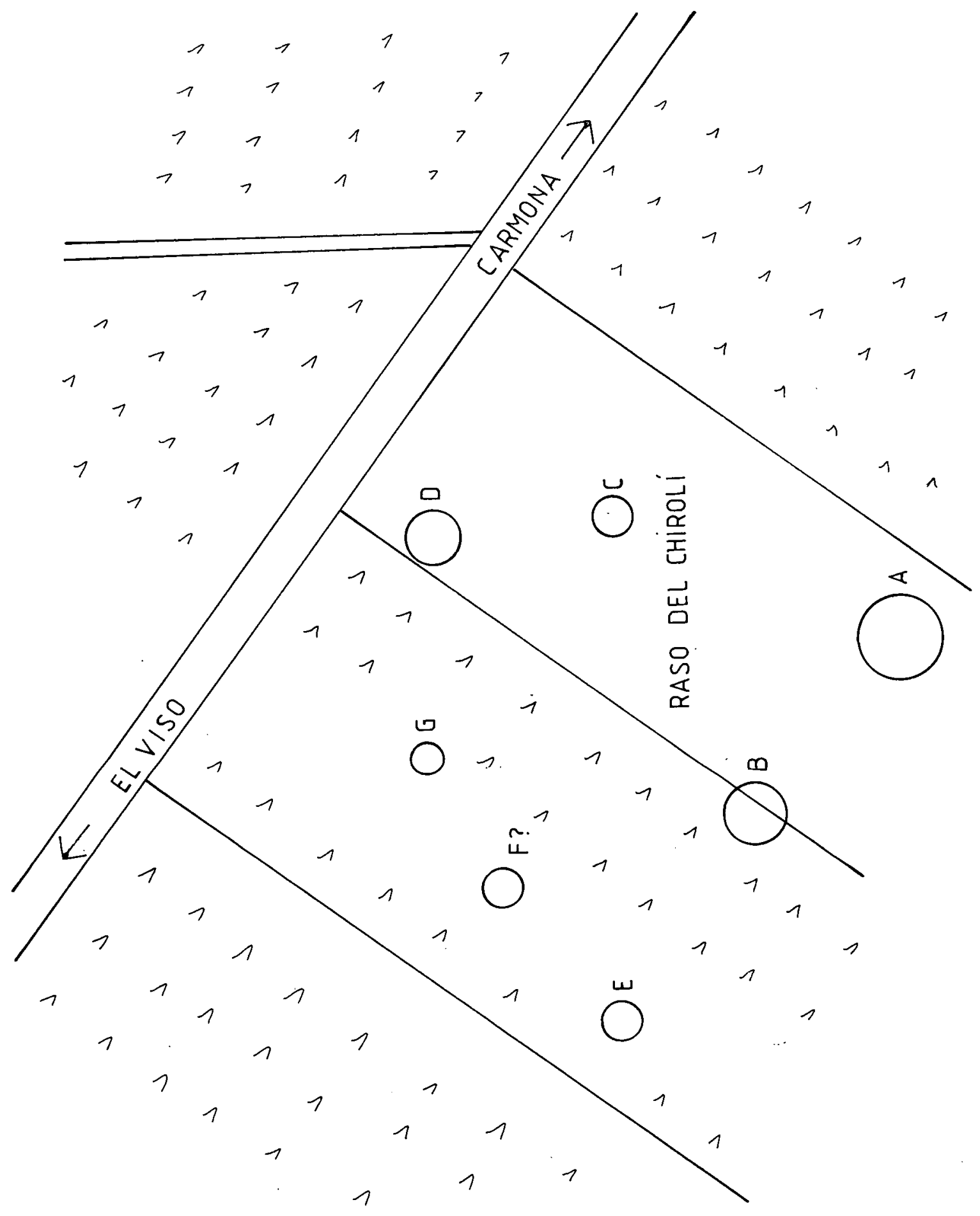

Fig. 3. Croquis de El Raso del Chirolí(según Bonsor). 

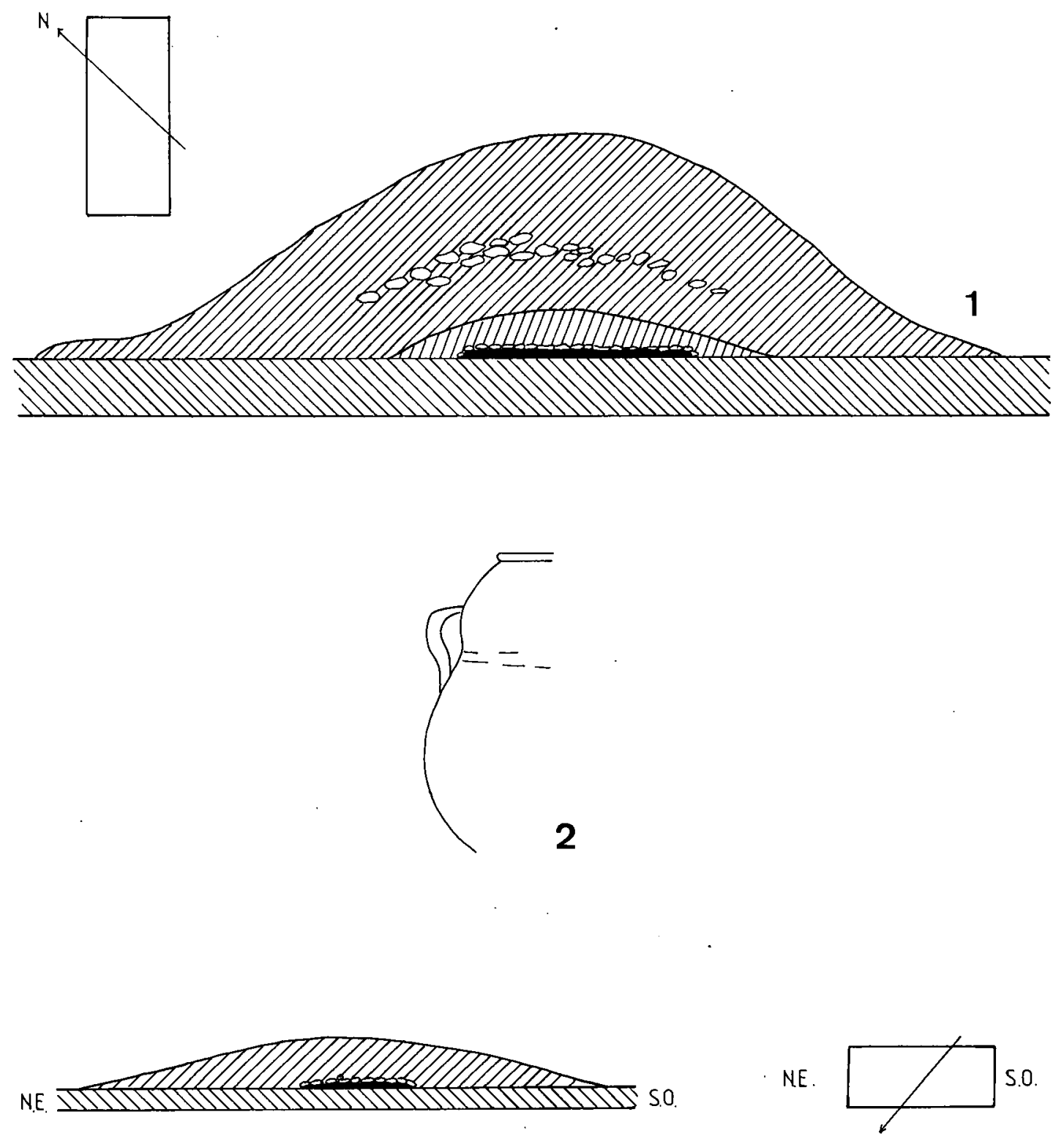

3

Fig. 4. I, Alzado del túmulo a y planta de la fosa. 2, Reconstrucción del ánfora que servía de cobertura. 3, Alzado del túmulo D y planta de la fosa (según Bonsor). 


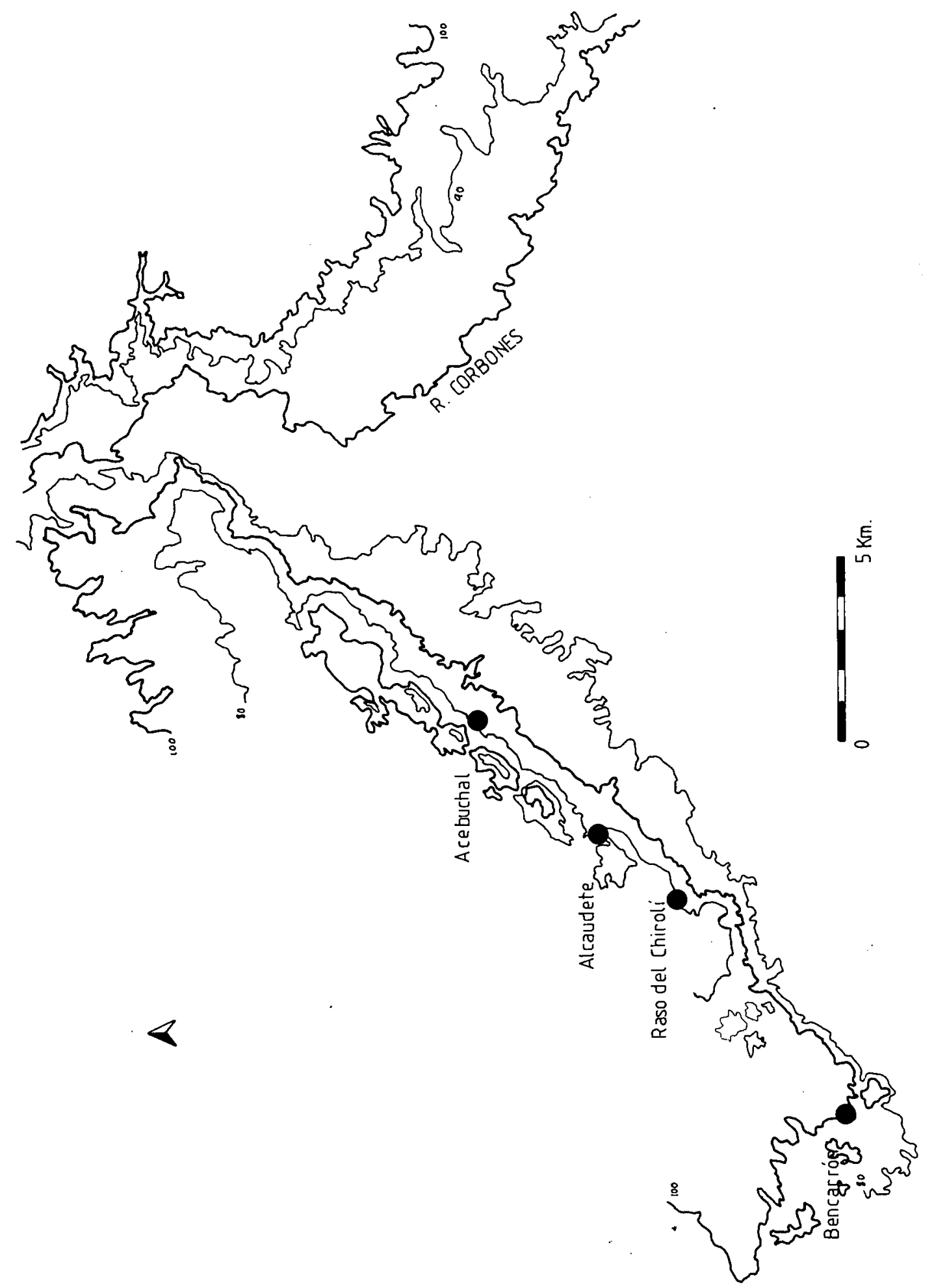

Fig. 5. Dispersión de los enterramientos con rituales similares a los de El Raso del Chirolí. 